\title{
Comunicação
}

[Communication]

\section{Primeiro relato do parasitóide Paraganaspis egeria Díaz, Gallardo e Walsh (Hymenoptera: Figitidae: Eucolinae) como inimigo natural de Archisepsis scabra (Loew) (Diptera: Sepsidae) em fezes de búfalos no Brasil}

\author{
[First report of parasitoid Paraganaspis egeria Díaz, Gallardo \& Walsh (Hymenoptera: Figitidae: Eucolinae) as \\ natural enemy of Archisepsis scabra (Loew) (Diptera: Sepsidae) in buffalo dung in Brazil]
}

\section{C.H. Marchiori}

Instituto Luterano de Ensino Superior de Itumbiara-ILES-ULBRA

Caixa Postal 23-T

75500-000 - Itumbiara, GO

A superfamília Cynipoidea apresenta cerca de 20.000 espécies, sendo aproximadamente $75 \%$ parasitóides de insetos holometábolos (Gauld e Bolton, 1988).

A subfamília Eucoilinae, apesar de cosmopolita, é pouco conhecida. Ela é representada por cerca de 1000 espécies e 70 gêneros espalhados pelo mundo (Nordlander, 1984). São endoparasitóides primários coinobiontes de larvas dípteros ciclorráfos, inclusive fitófagos. Encontram-se em grande número ao redor de estrumes, carcaças em decomposição e locais ricos em dípteros na região neotropical (Gauld e Bolton, 1988; Díaz e Gallardo, 1996).

O objetivo deste estudo é descrever a primeira ocorrência de Paraganaspis egeria como parasitóide de Archisepsis scabra no Brasil.

O experimento foi realizado na Fazenda da Faculdade de Agronomia, às margens do rio Paranaíba, a 5km de Itumbiara, GO.

Fezes frescas, marcadas imediatamente após sua emissão em pastagens de braquiária (Brachiaria brizantha) (Hoechst ex. A. Rich), com auxílio de estacas de madeira branca $(30 \mathrm{~cm}$ de altura e $5 \mathrm{~cm}$ de espessura), para determinação precisa do tempo entre a emissão e a coleta, permaneceram no campo por 15 dias. Foram coletadas e levadas para o laboratório do Instituto Luterano de Ensino Superior de Itumbiara, GO, para a extração das pupas pelo método da flutuação. Juntamente com as fezes, foram retirados $5 \mathrm{~cm}$ do substrato situado abaixo do local de deposição no solo. As pupas foram retiradas com o auxílio de uma peneira, contadas e individualizadas em cápsulas de gelatina (número 00) até a emergência das moscas e/ou dos parasitóides. Os parasitóides e as moscas emergidos, identificados com auxílio de um microscópio estereoscópio, foram conservados em álcool 70\%. Os espécimes coletados foram depositados na coleção entomológica do Departamento de Biologia do Instituto Luterano de Ensino Superior de Itumbiara. A porcentagem de parasitismo foi calculada pelo número de pupas parasitadas/número total de pupas coletadas $\times 100$.

No período de maio a junho de 2003, obtiveramse 116 pupários de Archisepsis scabra (Loew) (Diptera: Sepsidae), das quais emergiram quatro espécimes do parasitóide Paraganaspis egeria Díaz, Gallardo e Walsh (Hymenoptera: Figitidae: Eucoilinae). A porcentagem de parasitismo foi de $3,4 \%$, atribuídas, provavelmente, às variações na qualidade e na disponibilidade dos recursos alimentares ou à densidade dos hospedeiros.

Recebido para publicação em 25 de junho de 2003

Recebido para publicação, após modificações, em 22 de março de 2004

E-mail: pesquisa.itb@ulbra.br 
Reguladores naturais, como os parasitóides, podem ser usados no controle biológico de moscas. Esses agentes são responsáveis pela redução de populações de moscas sinantrópicas. Várias espécies de Eucoilinae têm sido relatadas como importantes inimigos naturais de diferentes espécies de dípteros (Wharton et al., 1998).

Foram encontradas $P$. egeria parasitando Chrysomya albiceps (Wiedemann) (Diptera: Calliphoridae) em carcaça de suíno, Palaeosepsis spp. (Diptera: Sepsidae) e Sarcophagula occidua (Fabricius) (Diptera: Sarcophagidae) em fezes bovinas e Fannia pusio (Wiedemann) (Diptera: Fanniidae) em fezes humanas, fígado bovino e vísceras de galinha (Marchiori et al., 2002).
A biologia da família Sepsidae é desconhecida para a região neotropical. As espécies dessa família são encontradas próximas a ou sobre fezes de animais, e as larvas desenvolvem-se em matéria orgânica em decomposição, sendo freqüentes em fezes bovinas (Amaral, 1996; Marchiori e Linhares, 1999; Marchiori, 2000; Marchiori et al., 2001).

Este trabalho descreve a primeira ocorrência de $P$. egeria como parasitóide de $A$. scabra no Brasil.

Palavras-chave: controle biológico, inimigo natural, fezes de búfalos, moscas

\begin{abstract}
This study is the first report of the occurrence of Paraganaspis egeria Díaz, Gallardo \& Walsh (Hymenoptera: Figitidae: Eucoilinae) as parasitoid of Archisepsis scabra (Loew) (Diptera: Sepsidae) in buffalo dung in Itumbiara, Goiás, Brazil. The samples were collected and taken to the laboratory for pupa extraction by water flotation technique. The pupae were individually placed in gelatin capsules until the emergency of the adults flies or their parasitoids. The parasitism percentage was $3.4 \%$.
\end{abstract}

Keywords: biological control, natural enemy, buffalo dung, flies, Brazil

\section{REFERÊNCIAS BIBLIOGRÁFICAS}

AMARAL, M.M.G. Dípteros simbovinos: colonização e sucessão em placas isoladas de fezes bovinas. 1996. 66f. Dissertação (Mestrado). Universidade Estadual de Campinas, SP.

DÍAZ, N.; GALLARDO, F. Sobre cinipoideos del Brasil, parasitoides de dipteros estercoleros (Hymenoptera: Cynipoidea). Rev. Soc. Entomol. Argent., v.55, p.127-129, 1996.

GAULD, I.D.; BOLTON, B. The Hymenoptera. New York: Oxford University, 1988. 331p.

MARCHIORI, C.H. Spalangia drosophilae Ashmead (Hymenoptera: Pteromalidae) como inimigo natural de Archisepsis scabra (Loew) (Diptera: Sepsidae) em fezes bovinas. Arq. Bras. Med. Vet. Zootec., v.53, p.663-665, 2001.

MARCHIORI, C.H.; LINHARES, A.X. Espécies de Eucoilidae (Hymenoptera: Cynipoidea) parasitóides de díptera associados com fezes bovinas. Arq. Inst. Biol. São Paulo, v.66, p.5962, 1999.
MARCHIORI, C.H.; PEREIRA, L.A.; SILVA FILHO, O.M. et al. Paraganaspis egeria Díaz, Gallardo \& Walsh (Hymenoptera: Figitidae: Eucoilinae) as potential agent in the biocontrol of muscoid dipterous collected in several substracts in Itumbiara, Goiás, Brazil. Arq. Bras. Med. Vet. Zootec., v.54, p. 662-664, 2002.

MARCHIORI, C.H.; SILVA, C.G.; LINHARES, A.X. Primeira ocorrência de Triplasta atrocoxalis Ashmead (Hymenoptera: Eucoilidae) em pupas de Cyrtoneurina pararescita Couri (Diptera: Muscidae) em currais de bovinos no Brasil. Arq. Bras. Med. Vet. Zootec., v.52, p.3940, 2000.

NORDLANDER, G. Vad vet vi parasitiska Cynipoidea. Entomol. Tidskr., v.105, p.36-40, 1984.

WHARTON, S.M.; 0VRUSKI, S.M.; GILTRAP, F.E. Neotropical Eucoilidae (Cynipoidea) associated with fruit-infesting Tephritidae, with new records from Argentina, Bolivia and Costa Rica. J. Hym. Res., v.7, p.102-115, 1998. 